\title{
PERBANDINGAN POLA PELETAKKAN TELUR KUPU-KUPU Eurema blanda (LEPIDOPTERA: PIERIDAE) PADA DUA SPESIES TANAMAN PAKAN LARVA DI TAMAN KUPU-KUPU GITA PERSADA
}

\section{THE COMPARISON OF BUTTERFLY'S EGG LAYING PATTERN ON TWO SPECIES OF LARVAE'S FEED PLANTS IN GITA PERSADA BUTTERFLY PARK}

Erika Oktavia Gindhi ${ }^{1 *}$, Herawati Soekardi ${ }^{1}$, Nismah Nukmal ${ }^{1}$

1Jurusan Biologi FMIPA Universitas Lampung

*erikaoktaviag14@yahoo.com

\begin{abstract}
ABSTRAK
Eurema blanda merupakan kupu-kupu dari famili Pieridae yang memiliki warna kuning dan bintik coklat pada sayapnya yang merupakan ciri khas dari kupu-kupu tersebut. Tujuan dari penelitian ini adalah untuk mengetahui perbandingan pola peletakan telur E.blanda pada dua macam tanaman pakan larva. Dua spesies tanaman pakan yang di gunakan yaitu tanaman kaliandra (Calliandra surinamensis) dan tanaman ketepeng (Cassia alata). Penelitian ini di lakukan di Taman Kupu-kupu Gita Persada yang terletak di Gunung Betung, Kemiling, Bandar Lampung, Provinsi Lampung, yang di lakukan pada bulan Januari sampai Maret 2016. Metode yang digunakan pada penelitian ini yaitu eksperimen dengan menggunakan 2 macam tanaman pakan larva yang masing-masing 10 polybag di letakkan berkelompok pada kandang penangkaran. Analisis data di lakukan dengan cara deskriptif kuantitatif dan uji independent samples test. Hasil penelitian menunjukkan kupu-kupu $E$. blanda meletakkan telur-telurnya secara berkelompok di daun termuda pada kedua tanaman pakan larvanya. Kelompok telur yang terdapat pada tanaman kaliandra dan tanaman ketepeng berbeda nyata $(p=0,007)$ setelah di uji menggunakan uji T. Kelompok telur pada kaliandra yaitu 1-3 kelompok dengan rata-rata jumlah telur per kelompok yaitu 31,50 $\pm 6,85$ butir sedangkan pada tanaman ketepeng 1-2 kelompok dengan rata-rata jumlah telurnya yaitu 40,84 \pm 11,02 butir. Rata-rata panjang telur berbeda nyata $(p=0,005)$ pada tanaman kaliandra yaitu $1,31 \pm 0,06 \mathrm{~mm}$ sedangkan pada tanaman ketepeng 1,28 $\pm 0,03 \mathrm{~mm}$. Rata-rata diameter telur tidak berbeda nyata $(p=0,569)$ pada tanaman kaliandra yaitu $0,75 \pm 0,11 \mathrm{~mm}$ dan pada tanaman ketepeng yaitu $0,76 \pm 0,09 \mathrm{~mm}$.
\end{abstract}

Kata kunci : Eurema blanda, telur, kaliandra, ketepeng

\begin{abstract}
Eurema blanda is a butterfly from Pieridae family which its characteristics are yellow body and has brown spots on its wings. This research was aim to know the comparison of $E$. blanda's egg laying pattern on two species of larvae's feed plants. The species of that two species were Calliandra surinamensis and Cassia alata. This research was done in Gita Persada Butterfly Park which located in Betung Mountain, Kemiling, Bandar Lampung, Lampung Province, This research was conducted on January until March 2016. The method that used in this research was experimental study where two species of larvae's feed plants within each of ten polybags in one group placed in breeding cage. Data analysis was performed in quantitative descriptive data and by using independent samples test. The result showed that $E$. blanda butterflies were placing there eegs on the youngest leaves in the two species of its larvae's feed plants. Egg groups on C. surinamensis and $C$. alata were significantly different $(p=0,007)$ after tested by using Ttest. One until three of egg groups on $C$. surinamensis had the mean of eggs number on each group was $31,50 \pm 6,85$ grains where as the mean of eggs number on each group in one until two of egg groups on $C$. alata was 40,84 $\pm 11,02$ grains. The means of egg's length were significantly different $(p=0,005)$ where in $C$. surinamensis had 1,31 $\pm 0,06$ $\mathrm{mm}$ length and 1,28 $\pm 0,03 \mathrm{~mm}$ length in $C$. alata. The means of egg's diameter were not significantly different $(p=0,569)$ where in $C$. surinamensis was $0,75 \pm 0,11 \mathrm{~mm}$ and is $C$. alata was $0,76 \pm 0,09 \mathrm{~mm}$.
\end{abstract}

Keyword : Eurema blanda, Egg, Calliandra surinamensis, Cassia alata 


\section{PENDAHULUAN}

Taman Kupu-kupu Gita Persada merupakan tempat konservasi kupu-kupu sumatera yang terdapat di Bandar Lampung. Kupu-kupu sumatera yang terdapat di Taman Kupu-kupu Gita Persada salah satunya adalah Eurema blanda (Soekardi et al., 2001). E. blanda memiliki ciri khas yaitu terdapat tiga bercak pada bagian pangkal sayapnya (Putri, 2004). Tanaman pakan E. blanda yang sering dijumpai pada Taman Kupu-kupu Gita Persada yaitu tanaman pakan kaliandra dan ketepeng. Kedua tanaman pakan larva tersebut sudah dibudidayakan di Taman Kupu-kupu Gita Persada untuk keberlangsungan hidup kupu-kupu tersebut (Soekardi et al., 2001).

Tanaman kaliandra dan tanaman ketepeng termasuk kedalam famili Fabaceae. Tanaman kaliandra mempunyai daun majemuk yang berpasangan dengan jumlah daun 20 pasang memiliki panjang 4-6 cm dan lebar daun 2-6 cm (Tangendjaja et al, 1992), sedangkan tanaman ketepeng mempunyai daun majemuk dengan jumlah daun antara 8 hingga 24 pasang memiliki panjang daun antara $3,5-15 \mathrm{~cm}$, dan lebar 2,5-9 cm (Rosdiana, 2015).

Tanaman kaliandra dan tanaman ketepeng memiliki ukuran, bentuk, dan luas daun yang berbeda. Tanaman kaliandra memiliki luas daun 8 - $36 \mathrm{~cm}^{2}$ sedangkan tanaman ketepeng luas daunnya yaitu $7,5-135 \mathrm{~cm}^{2}$. Adanya perbedaan dari kedua tanaman pakan tersebut diduga mempengaruhi pola peletakkan telur sehingga perlu di lakukan penelitian tentang pola peletakkan telur.

\section{BAHAN DAN METODE}

Penelitian ini dilakukan di Taman Kupu-kupu Gita Persada yang terletak di Gunung Betung yang dilakukan pada bulan Januari sampai Maret 2016. Metode yang digunakan pada penelitian ini adalah eksperimen dengan menggunakan masing-masing 10 polybag tanaman pakan larva yang diletakkan pada kandang penangkaran dan 5 pasang kupu-kupu E. blanda yang dilepaskan pada kandang penangkaran. Mikroskop stereo yang digunakan pada penelitian ini berfungsi untuk mengukur panjang dan diameter telur yang ada pada kedua tanaman pakan larva. Parameter yang diamati yaitu posisi telur yang diletakkan pada daun tanaman pakan, jumlah kelompok telur yang ada pada daun tanaman pakan, jumlah telur yang di hasilkan oleh induk E. blanda, dan morfologi telur pada tanaman pakan larva.

Data yang diperoleh dianalisa secara deskriptif kuantitatif dan uji Independent samples test yang dapat menjelaskan tentang pola peletakkan telur pada kedua tanaman pakan larva.

\section{HASIL DAN PEMBAHASAN Pola Peletakkan Telur pada Tanaman Pakan Larva}

Kupu-kupu E. blanda meletakkan telur pada permukaan bawah daun baik pada tanaman kaliandra maupun pada tanaman ketepeng. Pola peletakkan telur pada kedua tanaman pakan berbeda pada kaliandra telur diletakkan secara teratur dan rapi memanjang dari ujung daun hingga pangkal daun muda yang masih menguncup sedangkan pada tanaman ketepeng telur diletakkan mulai dari ujung daun 
mengelompok sampai bagian tengah daun ketepeng (Gambar 1).

Perbedaan pola peletakkan telur pada kedua tanaman pakan diduga karena ukuran panjang daun, lebar daun, dan luas daun berbeda. Tanaman kaliandra mempunyai daun majemuk yang berpasangan dengan jumlah daun 20 pasang memiliki panjang 4-6 $\mathrm{cm}$ dan lebar daun 2-6 cm (Tangendjaja et al, 1992), sedangkan tanaman ketepeng mempunyai daun majemuk dengan jumlah daun antara 8 hingga 24 pasang memiliki panjang daun antara 3,5-15 cm, dan lebar 2,5-9 cm (Rosdiana, 2015).

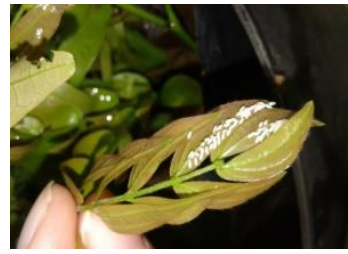

A

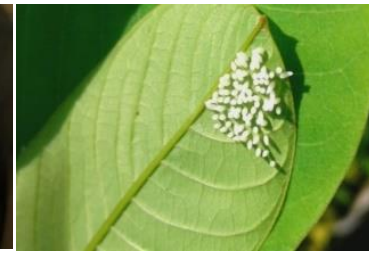

Gambar 1. Telur pada tanaman pakan larva yang di letakkan di permukaan bawah daun (A. Kaliandra, B. Ketepeng)

Posisi telur pada daun tanaman kaliandra berada dibawah permukaan daun ke 1 yang masih muda (Gambar 2). Posisi telur pada tanaman ketepeng berada dibawah permukaan daun ke 2. Tan (2015) juga menyatakan bahwa telur kupu-kupu Eurema blanda diletakkan pada bagian bawah permukaan daun tanaman pakan kaliandra dengan cara berkelompok.

Posisi telur yang diletakkan pada daun kaliandra dan daun ketepeng berada dibawah permukaan daun muda hal ini dikarenakan larva yang baru menetas akan lebih mudah memakan daun yang muda dengan sklereid yang tidak keras, sedangkan pada daun yang sudah tua sklereid (sel batu) yang berada pada daun sudah keras sehingga larva yang baru menetas susah untuk memakannya (Campbell.,dkk, 2006).

Pada Gambar 2 dapat dilihat bahwa kupukupu E. blanda sering meletakkan telurnya pada daun yang masih muda pada kedua tanaman pakan larva. Pada tanaman ketepeng diletakkan pada tangkai daun ke 2 dari pucuk dengan posisi pada daun $f$ dan $g$ sedangkan pada tanaman kaliandra di letakkan pada tangkai daun ke 1 dengan posisi pada daun j dan $\mathrm{k}$.

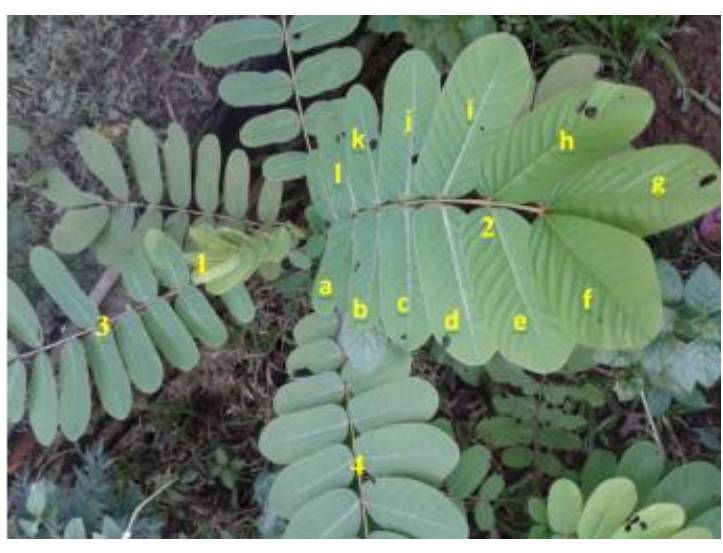

A

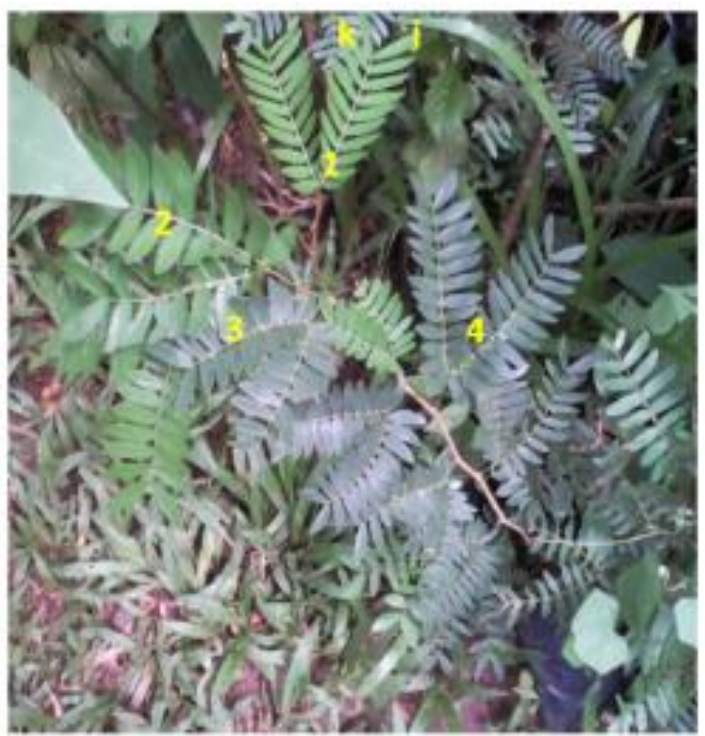

Gambar 2. Posisi telur yang diletakkan pada daun tanaman pakan ( $A$ Ketepeng ( $2 \mathrm{f}$ dan $\mathrm{g}$ ), B. Kaliandra (1 j dan k) 
Pada penelitian ditemukan telur E. blanda yang di letakkan pada petiolus daun tanaman ketepeng walaupun hanya terdapat satu kelompok saja. Pada petiolus daun tanaman ketepeng terdapat sebanyak 33 butir telur yang di letakkan oleh induk kupu-kupu $E$. blanda (Gambar 3).

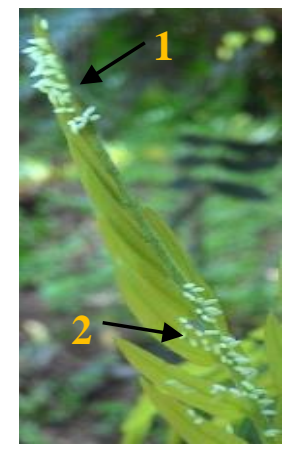

A

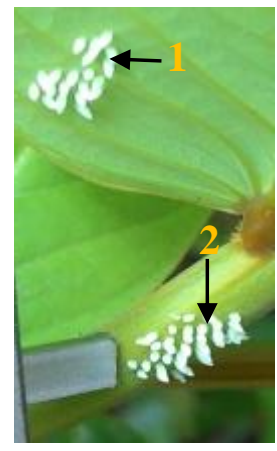

B
Gambar 3. Jumlah kelompok telur pada daun tanaman pakan larva yang berada dipermukaan bawah daun perbesaran $5 \times(\mathrm{A}$. Tanaman kaliandra (1. Daun yang menguncup, 2. Daun ke 5), B. Tanaman ketepeng (1. Petiolus daun, 2. Permukaan bawah daun ke 6)

\section{Jumlah Telur yang dihasilkan Oleh Induk}

Telur yang diletakkan bisa mencapai 100 butir pada daun muda kaliandra. Rata-rata telur yang di letakkan pada tanaman kaliandra yaitu sebanyak 56 butir. Waktu yang dibutuhkan untuk meletakkan telur sebanyak 100 butir yaitu selama 19 menit 24 detik. Pada daun muda ketepeng rata-rata telur yang diletakkan yaitu sebanyak 53 butir. Waktu yang dibutuhkan untuk meletakkan telur 100 butir yaitu selama 17 menit 14 detik. Pada pengamatan Tan (2015) menyatakan bahwa telur yang di hasilkan oleh 1 induk betina kupu-kupu E. blanda sebanyak 100 butir telur.
Rata-rata jumlah telur yang di letakkan pada kedua tanaman pakan larva tidak berbeda nyata $(p=0,795)$ setelah dilakukan uji menggunakan SPSS 16 for windows dengan cara independent samples test. Hasil disajikan pada Tabel 1.

Tabel 1. Rata-rata (butir $\pm s d$ ) jumlah telur yang diletakkan oleh induk pada 2 jenis tanaman pakan

\begin{tabular}{cc}
\hline Tanaman pakan larva & Jumlah telur \\
\hline Kaliandra & $56,70 \pm 32,69^{\mathrm{a}}$ \\
Ketepeng & $53,10 \pm 28,25^{\mathrm{a}}$ \\
\hline
\end{tabular}

Keterangan : angka yang di ikuti oleh huruf yang sama tidak berbeda nyata dengan uji T pada taraf signifikasi $5 \%$

Jumlah kelompok telur yang diletakkan induk pada tanaman kaliandra berkisar antara 1- 3 kelompok telur, rata-rata telur yang berada didalam kelompok yaitu 31,50 \pm 6,85. Sedangkan pada tanaman ketepeng jumlah kelompok telur yang dihasilkan oleh induk betina yaitu 1 - 2 kelompok telur. Jumlah rata-rata telur per kelompok yang ada didaun ketepeng yaitu 40,84 $\pm 11,02$. Hasil uji $T$ memperlihatkan adanya perbedaan nyata antara rata-rata jumlah telur yang diletakkan induk per kelompok antara daun kaliandra dan daun ketepeng $(p=0,001)$ (Tabel 2$)$.

Perbedaan jumlah telur pada kedua tanaman pakan larva mungkin disebabkan karena ukuran daun kedua tanaman pakan berbeda. Ukuran luas tanaman kaliandra yaitu yaitu 8 $36 \mathrm{~cm}^{2}$ sedangkan tanaman ketepeng luas daunnya yaitu $7,5-135 \mathrm{~cm}^{2}$. 
Tabel 2. Rata-rata (butir \pm sd) jumlah kelompok telur yang di letakkan pada 2 jenis tanaman pakan

\begin{tabular}{cc}
\hline Tanaman pakan & Jumlah kelompok telur \\
\hline Kaliandra & $31,50 \pm 6,85^{\mathrm{a}}$ \\
Ketepeng & $40,84 \pm 11,02^{\mathrm{b}}$ \\
\hline
\end{tabular}

Keterangan : angka yang di ikuti oleh huruf yang sama berbeda nyata dengan uji T pada taraf signifikasi $5 \%$

\section{Morfologi Telur pada Tanaman Pakan Larva}

Hasil uji T (Tabel 3) memperlihatkan rata-rata panjang telur E. blanda pada kaliandra berbeda nyata dengan ketepeng ( $p=0,005)$, sedangkan diameter telur tidak berbeda nyata $(p=0,569)$.

Panjang telur dan diameter telur pada 2 jenis tanaman pakan berbeda yang dikarenakan luas dari kedua tanaman pakan berbeda. Pada tanaman kaliandra mempunyai luas daun yaitu 8 - $36 \mathrm{~cm}^{2}$ sedangkan tanaman ketepeng luas daunnya yaitu 7,5 - $135 \mathrm{~cm}^{2}$. Dengan luas daun yang berbeda pada kedua tanaman pakan sehingga telur yang diletakkan memiliki perbedaan pada panjang telur dan diameter telur.

Tabel 3. Rata-rata ( $\mathrm{mm} \pm \mathrm{sd}$ ) pengukuran panjang dan diameter telur pada tanaman kaliandra dan tanaman ketepeng

\begin{tabular}{ccc}
\hline $\begin{array}{c}\text { Tanaman } \\
\text { pakan }\end{array}$ & Panjang telur & Diameter telur \\
\hline Kaliandra & $1,31 \pm 0,06^{\text {a }}$ & $0,75 \pm 0,11^{a}$ \\
Ketepeng & $1,28 \pm 0,03^{\mathrm{b}}$ & $0,76 \pm 0,09^{\mathrm{a}}$ \\
\hline
\end{tabular}

Keterangan : angka yang di ikuti oleh huruf yang sama pada kolom yang sama tidak berbeda nyata pada uji T taraf signifikasi $5 \%$

Telur E.blanda berwarna putih dan berbentuk lonjong pada kedua jenis tanaman pakan (Gambar 4) hal ini sesuai dengan hasil pengamatan Tan (2015) yang menyatakan telur E.blanda memiliki warna putih dengan bentuk tabung lonjong.

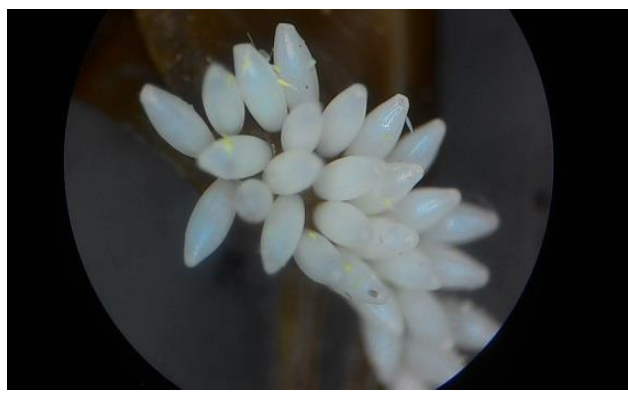

A

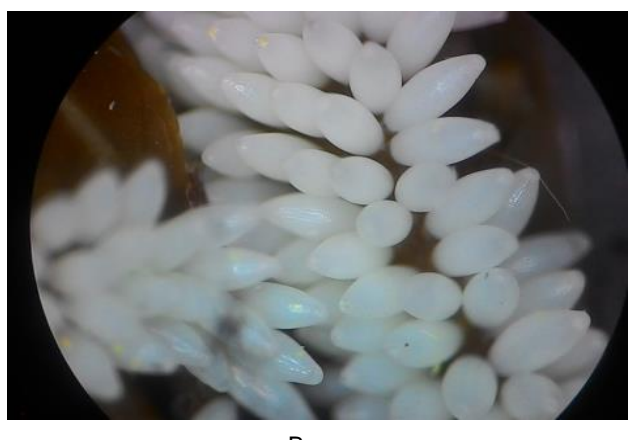

Gambar 4. Telur pada tanaman pakan larva yang diamati dimikroskop stereo dengan perbesaran $40 \times$ ( $\mathrm{A}$. Kaliandra, B. Ketepeng)

\section{SIMPULAN}

Kesimpulan yang diperoleh dari penelitian ini adalah Eurema blanda meletakkan telurtelurnya secara berkelompok pada daun termuda kedua tanaman pakan larvanya. Kelompok telur pada kaliandra yaitu 1-3 kelompok dengan rata-rata jumlah telur per kelompok yaitu $31,50 \pm 6,85$ butir sedangkan pada tanaman ketepeng 1-2 kelompok dengan rata-rata jumlah telurnya yaitu 40,84 $\pm 11,02$ butir. Rata-rata panjang telur berbeda nyata $(p=0,005)$ pada tanaman kaliandra yaitu 1,31 \pm 0,06 $\mathrm{mm}$ sedangkan pada tanaman ketepeng 1,28 $\pm 0,03 \mathrm{~mm}$. Rata-rata diameter telur tidak berbeda nyata ( $p=0,569$ ) pada tanaman kaliandra yaitu $0,75 \pm 0,11 \mathrm{~mm}$ dan pada tanaman ketepeng yaitu $0,76 \pm 0,09 \mathrm{~mm}$. 


\section{DAFTAR PUSTAKA}

Campbell, N.A., J.B. Reece, dan L.G. Mitchell., 2006. Biologi. Campbell edisi kelima jilid 2. Erlangga. Jakarta

Judarwanto, 2011. Biodiversitas Indonesia. \{Internet\}. Diunduh pada Senin 2 November 2015. Tersedia pada: www. Academia.edu/1346470/BiodiversitasIndonesia-Edisi 1-2-2011.

Putri, W, E. 2004. Keanekaragaman Kupukupu Coliadinae (Lepidoptera : Pieridae) Di Taman Nasional Siberut, Mentawai. (Skripsi). Jurusan Biologi. Universitas Andalas, Padang

Rosdiana, 2015. Ketepeng Cina Ciri-ciri Khasiat dan Manfaatnya \{Internet\}. Diunduh pada 24 Agustus 2015. Tersedia pada: http://www.tanobat.com/ketepeng-cinaciri-ciri-tanaman-serta-khasiat-danmanfaatnya.html.
Soekardi,

H.,Djausal.A.,Sastrodihardjo.S.2001. Taman Kupu-kupu Terbuka

Di Desa Tanjung Manis Gunung Betung Lampung Sebagai Suatu ModelKonservasi Kupu-kupu. Makalah disajikan dalam seminar hasil Penelitian Dosen Unila Tahun 2001.

Tan, H.2015. Life History of the Three Spot Grass Yellow (Eurema blanda snelleni). \{Internet\}. Diunduh pada Rabu 21 Oktober 2015. Tersedia pada :http://butterflycircle.blogspot.co.id/201 5/01/life-history-of-three-spot-grassyellow.html.

Tangendjaja, B. E. Wina, T. M. Ibrahim, dan B. Palmer. 1992. Kaliandra (Calliandra calothyrsus) Dan Manfaatnya. Balai Penelitian Ternak dan The Australian Centre For International Agricultural Research. P 13-42.s 